\title{
DE GODSDIENST DER BOSCHNEGERS
}

DOOR

L. JUNKER

I

In een vroeger in dit tijdschrift verschenen opstel over de boschnegers in Suriname ${ }^{1}$ ) werd aangetoond dat bij dit volk niets met zekerheid bekend is omtrent zijne afstamming van afrikaansche volken of stammen. Bij nader onderzoek naar het psychische leven komt men echter met tal van overleveringen in aanraking die den weg terug naar Afrika aanwijzen en is het zeer waarschijnlijk dat de met afrikaansche toestanden bekende ethnoloog menig punt van aanknooping zal weten te vinden ${ }^{2}$ ).

Bij het nederschrijven van hetgeen ik omtrent den godsdienst en de daarvan afhankelijke zeden en gebruiken ben te weten gekomen heb ik in de eerste plaats op het oog de meerdere bekendheid met de ware toestanden in het boschland van Suriname te bevorderen. Het psychische leven der boschnegers oefent eenen hoogst nadeeligen invloed op het sociale leven uit; bijzonder de naleving der lijk- en rouwgebruiken is oorzaak van den zeer slechten economischen toestand aldaar. Zeer dikwijls wordt in de nieuwsbladen melding gemaakt van hongersnood, moorden, verzet van hoofden enz. In het algemeen beoordeelt men deze feiten alleen naar de voor de overige samenleving in de Kolonie waarneembare verschijnselen en naar de rechtsopvattingen der westersche beschaving.

1) 5 e jg. blz. 310 .

2) Zie: „A Arikanische Relikte und Indianische Entlehnungen in der Kultur der Buschneger Surinams". Eine vergleichende ethnographische Studie von Gerhard Lindblom. Göteborg. 1924. 
Men begrijpt de foeka (pyschische nood) der boschnegers niet omdat men onbekend is met de zielstoestanden, met de duizende verwarde voorstellingen van machten die onbarmhartig in het leven van den mensch ingrijpen. Vastgeklonken in de boeien dezer voorstellingen en gebonden aan de instellingen van de familie en den onderstam kan niemand, ook de hoofden niet, anders handelen dan dezen ingeven of bepalen. Zoodoende wordt dikwijls onwil verondersteld waar in werkelijkheid onmacht aanwezig is ${ }^{\mathbf{1}}$ ).

Telkens wanneer bij bespreking der verschillende godsdienstuitingen door de laatsten het sociale leven der boschnegers meer of minder wordt beïnvloed of wanneer dezen als de oorzaak van toestanden, welke te recht als wantoestanden moeten worden aangemerkt, moeten worden beschouwd, zal ik trachten het verband aan te toonen.

Ten slotte nog eene opmerking. In het vorenstaande wordt gesproken van godsdienst der boschnegers. Dit is in strijd met mijne vroegere opvatting, weergegeven in „Eenige mededeelingen over de Saramaccaners" 2).

$\mathrm{Na}$ de nadere kennismaking met het religieuse leven der boschnegers ben ik van mijne meening terug gekomen, daar mij gebleken is dat vele handelingen niet zoo zinneloos zijn als dezen zich mij bij oppervlakkige beschouwing voordeden, en omdat, wat de hoofdzaak is, aan het godsdienstige beginsel afhankelijkheid van en onderwerping aan eene bovenzinnelijke macht in alle uitingen voorhanden is.

Teneinde den lezer een beter overzicht te verschaffen, zullen de godsdienstuitingen der boschnegers in twee groepen worden verdeeld en wel in zulke die alle boschnegers gemeenzaam bezitten en in zulke die slechts het geestelijk bezit van eenige onderstammen uitmaken.

2) Het lijdelijk verzet tegen elk onderwijs vloeit voort uit de overdreven zorg om de onafhankelijkheid. Men vreest dat het jonge geslacht de instellingen der vaderen zal leeren verachten en dat de kinderen door onderwijs te genieten tot gewillige werktuigen der blanken worden.

De verdediging der eenmaal verworven rechten strekt den boschnegers in ieder geval tot eer, al ziet men verachtend of medelijdend op de middelen neer, die zij gebruiken om hunne vrijheid te behouden.

2) $\mathrm{Zie}$,De West-Gids”, 4e jg. blz. 449. 
In de eerste der bovengenoemde groepen moeten worden opgenomen :

1. Het begrip van den hoogsten geest als schepper.

2. Het geloof in de geesten.

3. De vereering der voorouders.

4. Het geloof aan bezit van magische kracht, welke aan voorwerpen wordt toegekend, die van nature daartoe zijn bestemd of van geestenmacht, die uitgaat van voorwerpen welke door kunstmatige bewerking (tooverij) eenen geest als woning worden aangewezen.

Twee voorstellingen behooren nog in deze groep tehuis, de Kina en de Koenoe. Beiden dragen een godsdienstig karakter.

De hoogste geest is geen god die een centrale plaats in de wereldbeschouwing der boschnegers (zoo men dit woord met het oog op het beperkte, aan hunne naaste omgeving gebonden beschouwingsleven mag gebruiken) inneemt.

Als schepper heeft hij hemel en aarde en alles wat op de laatste is in het leven geroepen door eene plotselinge daad, en daarna de heerschappij over de aarde overgedragen aan de geesten. Geen enkel scheppingsverhaal geeft uitlegging; Sabianpoenkoe of Grangado, zooals de Saramaccaners den schepper noemen of Nana ${ }^{\mathbf{1}}$ ) zooals hij bij de Aucaners heet, heeft het gedaan en daarmede neemt de boschneger genoegen.

\footnotetext{
1) Grangado is de in Suriname aangenomen naam, Gran = groot, gado $=$ God.

Sabianpoenkoe is van afrikaanschen oorsprong. Nana is een woord uit het Tschi, eene taal die door een aantal negerstammen van de Goudkust wordt gesproken en beteekent grootvader.

Wie uit het laatste zal willen afleiden dat dus de Aucaners van de Goudkust afstammen moet nog het volgende weten:

Gwangwella is de naam van den hoofdfetisch der Aucaners. Omdat men dezen naam niet gaarne uitspreekt wordt de benaming Grantata algemeen gebruikt.

Gwangwella is de naam van eenen stam der Bantoevolken, welk laatste Afrika zuid van den Congo bewonen.

Tata $=$ vader is een woord uit het Tiote, eene taal die door een aantal stammen van het oude Loangorijk wordt gesproken. De Loango zijn eveneens geen echte negers doch behooren tot de Bantoe.

De Cromantijnen kunnen vermoedelijk in Afrika niet met Gwangwella bekend geweest zijn, omdat zij tot de echte negers hebben behoord die noord van den Congo hebben gewoond.
} 
Men kan evenmin van den schepper als van een opperwezen of heerscher spreken, als dat men aan de geheele voorstelling den naam van geloof kan toekennen.

Voor den hoogsten geest is geen eeredienst ingericht, men offert niet aan hem en roept hem slechts hoogst zelden aan.

In $1920 \mathrm{mij}$ aan de Pikienrio ophoudende was ik getuige van de toepassing van een godsoordeel (Kondre sooi) waarbij men Grangado aanriep.

Later onderzoek instellende waarom het laatste had plaats gehad vernam ik het volgende: Het aanroepen was louter eene gewoonte en heeft geene betrekking op de uitspraak die verwacht werd. „Na sondi” (het ding, de geest) zoo legde mij een oude neger uit „na gaman boeta na ini na kondresooi doe na wroko" (hetwelk degranman in het drankje heeft gedaan, bewerkt de uitspraak). Verder vertelde mij de neger nog: ,Wij offeren niet aan Grangado om dat hij ons goed noch kwaad doet. Waarom zouden wij hem dan aanroepen daar wij overtuigd zijn dat hij ons niet helpt. Grangado heeft eenmaal de winti (geesten) en de Gransembe (voorouders) aangewezen zich met ons boschnegers te bemoeien en daarbij is het altijd gebleven.

Terwijl dus de voorstelling van den hoogsten geest slechts een begrip is die de oorzaak van het bestaan verklaart ${ }^{1}$ ), gelooven de boschnegers onvoorwaardelijk in het bestaan der geesten en dat dezen het geheele leven der menschen beheerschen.

De geesten bewonen de aarde, het water ,het bosch en alle voorwerpen op of in deze, zooals steenen en rotsen,

$\left.{ }^{1}\right)$ Het zoude echter geen zuiver boschnegerbegrip zijn wanneer deze niet voor tegenspraak vatbaar was. Zoo hadden wij eens aan de Granrio een pingo (boschvarken) geschoten. Een van mijne arbeiders wilde de ingewanden in de rivier werpen toen een boschneger toesprong dezen opving en daarmede het bosch insnelde.

De boschneger keerde iets later terug en ik, vermoedende dat zijne daad in verband met eene Kina stond, vroeg hem naar de beweegredenen daarvan. Hij antwoordde: Massa ik heb de ingewanden aan den aasgier gebracht. Hij zal daarvan smullen en van uwe goedheid aan Grangado mededeeling doen. Laatstgenoemde zal niet in gebreke blijven U spoedig weder een andere pingo te doen toekomen. 
boomen, watervallen en kreeken, kortom ieder bijzonder in het oog vallend voorwerp dat iets vreemds, geheimzinnigs of ontzagwekkends aan zich heeft. Behalve dit groote leger geesten welke aan bepaalde plaatsen zijn gebonden zwerven op aarde nog rond de geesten van overleden menschen die wegens hun slecht gedrag niet bij de voorouders zijn opgenomen. Ook de meeste dieren worden geacht geesten te bezitten die invloed op de menschen uitoefenen ${ }^{1}$ ).

Alle geesten welke de natuur bewonen worden winti genoemd, terwijl voor sommigen ook de naam gado gebruikelijk is. De geesten der afgestorvenen noemt men jorka.

De geesten bezitten alle karaktereigenschappen der menschen. Zij zijn gierig en nukkig, licht geraakt en wraakzuchtig, sommigen laten zich gemakkelijk overhalen om den mensch van dienst te zijn, anderen weder zijn halsstarrig en veeleischend. Slechts weinigen hunner worden als goedaardig beschouwd.

Omdat de meeste winti dus zeer kwaadaardig van aard zijn leeft de boschneger in voortdurenden angst en ieder voorval in zijn leven, tegenspoed, ongesteldheid, ziekte en dood, alles, schrijft hij aan den invloed der geesten toe. Wel kan hem de natuurgenoot ook door tooverij schade toebrengen en koelt de koenoe zijne wraak op hem, doch zijn ook hierbij geesten in het spel. Nooit weet de boschneger of zijne offergave den winti, dien hij noodig heeft, heeft tevreden gesteld of dat hij onbewust een der geesten heeft beleedigd. De boschneger verkeert dus in

$\left.{ }^{1}\right)$ De geesten van sommige dieren worden geacht door de levenswijze van het betreffende dier kennis te hebben gekregen van de geneeskrachtige middelen als kruiden, boomschors enz. Door deze geesten bezeten menschen oefenen daarom de geneeskunde uit. De daarmede gepaard gaande handeling, men noemt het kortweg winti dansen, komt later nog ter sprake.

Geesten van dieren die bijzonder vaak opgeroepen worden zijn de geest van den Jaguar (Jaîni) de geest van den aasgier (Opete) en de geest van eene mooi geteekende boa, in de kolonie Papasneki genoemd.

De werkelijke drager van den tijgergeest is een groote tijgerkat, die men zeer zelden in het oerwoud ontmoet. Ook de werkelijke Opete is geenszins de gewone aasgier, die men in de kolonie stinkvogel noemt.

Van beide dieren wordt geloofd dat zij door menschen niet gedood kunnen worden; op hen gerichte, geladen geweren gaan niet af. 
voortdurende foeka ${ }^{1}$ ). Teneinde eenigszins gerust te kunnen zijn houdt hij dus voortdurend "Godsdienstoefeningen" zooals wij in het boekje van den heer van Lier op blz. 12 lezen.

Sommige winti zijn op bijzondere lekkernijen gesteld. Zoo houdt de Gron- of Papawinti veel van suikerwater en de kromantigado moet met heel veel sterke rum bediend worden; de door den geest der geneeskunde bezeten neger gaat niet tot behandeling over alvorens hij half dronken is.

Het eerste kwam ik op volgende wijze te weten: op zekeren dag was ik den geheelen dag uit jagen geweest en kwam tegen den avond met leege handen tehuis. Ik gaf mijn ongenoegen over mijn pech aan een van mijne boschnegers te kennen. Den geheelen avond draaide deze neger om mij heen als wilde hij mij over iets bijzonders spreken. Eindelijk kwam het er uit. Nadat hij eenige malen gehoest had begon hij: Massa u moet me niet kwalijk nemen ik moet $\mathrm{u}$ wat zeggen. De Granwinti van deze plaats moet $\mathrm{u}$ wild verschaffen. Hij geeft echter slechts wanneer hem wat gegeven wordt. $U$ is een blanke en $u$ gelooft niet aan deze dingen. Probeeren kunt $\mathrm{u}$ het echter. De winti houdt veel van suikerwater en hoe witter de suiker was, hoe vrijgeviger hij gestemd wordt. Maak morgen ochtend een kommetje suikerwater en stort het langzaam over den grond uit. Daarbij moet u zeggen: Ik ben een blanke en ben met je gewoonten niet bekend, Neem dit heerlijke suikerwater van mij aan en geef mij heden daarvoor in ruil wild.

Ik zeide aan Sotia dat ik morgen niet ging jagen doch dat ik het op een anderen dag zoude probeeren.

Hoe een geest op andere wijze dienstbaar gemaakt kan worden leert de geschiedenis van het grootopperhoofd Jankosoe. De oom van den granman Witiwojo, Bakiti, kwam op een dag bij een moeras terecht in welks midden een reusachtige bananenboom stond. Aan den boom hing een rijpe twaalfhands bos. Dezen kapte hij af en toen hij daarmede gereed was voelde hij dat een geest in hem was

1) Foeka = zorg, nood. 
gevaren, die hem duizelig maakte en hem van zijne omgeving niets liet onderscheiden. Bakiti smeekte den geest hem los te laten en zijne zuster Jaja, de vrouw van het grootopperhoofd Bosman te bezoeken. De geest luisterde naar de smeekbede en voer onmiddellijk in genoemde vrouw.

Laatstgenoemde behoorde tot den stam der Matjannegers en zij koesterde slechts één wensch, dat haar zoon Witiwojo het grootopperhoofd zoude opvolgen, om zoodoende haren stam de waardigheid te doen toekomen. Volgens de instellingen der boschnegers kon dit niet; ze nam daarom den geest van den bananenboom te hulp. Laatstgenoemde verlangde dat men hem het zand uit de voetspoor van het grootopperhoofd zoude brengen. Toen dit geschied was werd van bananen van den boom een tomtom (gestampte gekookte bananen) gestampt, het zand er in gedaan en daarna eene figuur er uit gekneed die den Granman Bosman moest voorstellen. De figuur werd door Jaja in eene diepte van de Pikienrio geworpen en daarbij zeide de geest: Niet voordat iemand deze pop uit de diepte ophaalt zal een ander Granman dan een Matjanneger de Saramaccaners regeeren.

Bosman stierf en werd Koenoe voor de grootopperhoofden uit den stam der Matjan. Hierover zullen wij het later hebben. De overlevering omtrent de opvolging der grootopperhoofden is weergegeven in „Eenige mededeelingen over de Saramaccaners".

Zooals wij uit het vorenstaande hebben geleerd kan een geest bezit nemen van een mensch. Dit geldt voor alle geesten.

Op het Christendorp Aurora ontmoette ik nog kort geleden eene vrouw die volgens mijn inzicht aan epileptische toevallen lijdende is. De dorpsbewoners zijn van andere meening. $Z$ ij vertelden mij dat voor ongeveer twintig jaren de zendeling $\mathrm{Zug}$ van de Moravische Broedergemeente den op het dorp staanden Kankautrie had laten vellen. De Gedehoesoe die dezen boom bewoond had voer in deze vrouw en nog een andere persoon en doet door dezen veel onheil over het dorp komen. 
De vrouw blijft gedurende langen tijd heel goed en wanneer de toevallen komen dan zeggen de bewoners van het dorp Na gado kisi en (God (Gedehoesoe) heeft bezit van haar genomen).

Het lijkt mij toe dat alle personen die door geesten bezeten worden door een defect in hun zenuwstelsel voorbeschikt zijn in den toestand te geraken die hier nader besproken zal worden, tenminste voor zoover er geen bedrog in het spel is. Zulke personen suggereeren zich eenen geest of meerdere geesten naar aanleiding van eenen droom of na eene gebeurtenis waarvoor zij geene verklaring kunnen vinden en die hun zenuwen diep geschokt heeft. Kinderen bezitten geen winti; meestal bezoeken de geesten personen van rijperen leeftijd, menschen aan wier zenuwen reeds door de uitspattingen van een dierlijk sexueel leven de knock out is toegebracht.

Het door eenen geest bezeten worden, dus de eigenlijke aanval, is voor de betreffende personen een toestand die verbazend veel van hun lichaam eischt. Ik heb gezien dat personen na een winti-aanval twee à drie dagen totaal uitgeput in de hangmat bleven liggen. Altijd hebik de vreemde uitdrukking, een wezenloos staren, in de oogen opgemerkt, die men bij krankzinnigen kan waarnemen. De toestand kan op twee wijzen zijn aanvang nemen: of de geest overvalt, zooals de boschnegers zich uitdrukken, zijn slachtoffer of hij wordt door het eigenaardige slaan op de kleine trom, Apinti genoemd, opgewekt, geroepen. Slechts de Kromantigado is voortdurend aanwezig in de persoon die zijne kunst uitoefent.

Het slaan op de trom begint met eene eigenaardige klankmaat, dof, stootend komen de eerste geluiden uit het instrument voort. Langzamerhand wordt het tempo sneller en eindigt met een razend vlugge roffel die nu en dan door eenige forsche slagen op de trom tijdelijk wordt afgebroken, doch meestal wel een kwart uur aanhoudt.

De persoon die straks bezeten zal worden zit meestal op een laag bankje in de nabijheid van den tromslager. Dikwijls merkte ik op dat de betreffende in een lustelooze 
stemming scheen te verkeeren; hij zat erbij als iemand die overlegt of hij hetgeen van hem gevergd wordt wel zal tot uitvoering brengen. De eerste toonen der apinti brengen verandering in de houding. Groote onrust maakt zich meester van de persoon, zij staat op, gaat weder besluiteloos zitten, tot zij na een wederom opstaan met weifelende schreden de open ruimte betreedt. Naarmate de maat van de trom sneller wordt, beginnen ook de lichaamsbewegingen in snelheid toe te nemen. De bezetenen beginnen, al naarmate de lichaamsbewegingen welke de betreffende geest gedacht wordt uit te voeren, te springen, te kruipen met de handen en armen als met vleugels te slaan, razend vlug in de ronde te draaien enz. Daarbij brullen, gillen en schreeuwen de bezetenen. Terwijl rust wordt gehouden zitten de meesten, zooals ik het in 1920 te Pikienslee bij eene winti-vertooning en massa zag, versuft op hunne bankjes, anderen daarentegen storten reeds na den eersten aanval bewusteloos neer; ik zag eene vrouw die weggedragen werd, wier geheele lichaam door hevige zenuwschokken werd bewogen en wier mond en neus met wit schuim waren bedekt. De omstanders hoorde ik zeggen: Na gado kisi en litti (God heeft haar goed te pakken). Dat er echter ook veel bedrog in het spel is bemerkte ik eveneens dien avond. Een man voerde den vuurdans uit. Hij danste met zijne bloote voeten in het vuur en zal, altijd volgens de opvatting der boschnegers, zijne voeten nooit verbranden zoolang de geest in hem is. In het algemeen wordt aangenomen dat bezetenen, gedurende het bezoek van den winti of gado aan hun lichaam, voor pijnen ongevoelig zijn. Dit is aanneembaar voor degenen voor wie het bezeten zijn een pathologische toestand is, de vuurdanser was echter een bedrieger. Ik sloeg hem in het bijzonder gade en merkte op dat zijne sprongen wel berekend waren en hij wel vlug door de vlam van het vuur sprong, doch goed uitkeek om niet in de gloeiende houtskool terecht te komen. Toen de vlam eens heel wat oplaaide nam hij eenen hoogen sprong met het gevolg dat hij zijn hoofd geducht aan een balk van de groote open hut stootte. Ik zag toen zijne handen naar zijn hoofd 
beschouwd door geesten uitverkoren te zijn om hen nu en dan tot huisvesting te dienen.

Als bijzonder wraakzuchtige geesten worden gevreesd de Ampoekoe of Kantamassoe, welke houtluizennesten bewoont die in staat van ontbinding verkeeren en hierbij groote hoeveelheden wit schuim doen opborrelen, de Gedehoesoe welke den Kankantrieboom bewoont ${ }^{1}$ ), Kolokwee die zijne huisvesting heeft in een boom, Katoe genoemd, de geesten van eenige watervallen, kreken enz.

In Maart van de Pikienrio terugkeerende merkte ik de monding van eene kreek op waarvan de naam mij ontschoten was. Ik vroeg daarna aan den achter mij aan het stuur zittenden boschneger. Hij gaf voor den naam niet te weten. Wel een kilometer van de plaats verwijderd zijnde sprak mij de boschneger aan: Massa ik weet dat u kwaad op mij is omdat u mij zooven op een leugen betrapt hebt. Ik woon hier, dus ik moet den naam van de kreek weten. Massa het is de Daliekreek. Daarginds kon ik den naam niet uitspreken. De Winti van de kreek is uiterst kwaadaardig. Had hij gehoord dat ik den naam van zijn woonplaats had genoemd, dan zou hij mij zeer zeker heel veel kwaad doen.

Zoo kan men een boschneger op een waterval niet meer van streek brengen dan wanneer men naar den naam daarvan vraagt. Beter is zulks niet te doen; de boschnegers verliezen daardoor de op de vallen hoogst noodige tegenwoordigheid van geest, het geen voor alle opvarenden noodlottige gevolgen kan hebben.

Het bestek van het opstel verbiedt verder op dat onderwerp in te gaan. Het zoude boekdeelen vullen, wilde men al de psychische verschijnselen bespreken welke aan de duizende wilde, verwarde voorstellingen der boschnegers hun ontstaan te danken hebben. Slechts wanneer eenig stelsel in de denkbeelden waar te nemen is of wanneer fantasiegedrochten grootere complexen hebben veroverd en zoodoende geestelijk eigendom van de gemeen-

1) Niet iedere Kankantrie wordt door Gedehoesoe (of Gedewsoe) bewoond; het zijn door vorm of grootte onderscheiden boomen alleen, die geacht worden den geest tot woonplaats te dienen. 
varen en de voor pijnen ongevoelige vuurdanser ging met de handen aan zijn hoofd stilletjes zitten, lang voor dat het hoogte punt van den heksensabbat was bereikt.

De geest van den Loangogado of Ania doet zijne aanwezigheid in een persoon op geheel andere wijze kennen. De betreffende persoon wordt bevangen van hetgeen men in de kolonie stille trekken noemt, een zenuwtoeval gedurende welken de daaraan lijdenden doodstil liggen en slechts verschillende spiergroepen in schokkende beweging verkeeren. Uit deze bewegingen verklaart de fetischpriester den wensch der obia of leest hij de namen der kruiden die als medicijn moeten worden gebruikt.

Het gebeurt heel dikwijls dat de stilte van den nacht plotseling door vreeselijk gillen en schreeuwen wordt verbroken en in een ommezien zijn alle bewoners van het dorp vergaderd om de hut waaruit de geluiden voortkomen, teneinde te vernemen welke wenschen of bevelen de geest te kennen geeft, die in den bewoner of de bewoonster der hut is gevaren. Dat ook hierbij veel bedrog in het spel is, heb ik vaak kunnen nagaan. Zoo kwam eens een bewoner van de Tapanahony op bezoek in de Coermotibo. Hij was zeer verlangend naar eene vrouw doch men wilde hem geene afstaan. Een geest hielp hem uit zijne foeka (nood). Deze gelastte eenvoudig dat aan hem, den man op bezoek, eene vrouw moest worden gegeven, en zoo geschiedde het ${ }^{\mathbf{1}}$ ).

Onder de creolen-bevolking aan de Bovenrivieren, bijzonder in de Para speelt de winti eene groote rol. Te Bergen dal woont een man die niet minder dan acht winti's bezit. Ook op de goudplacers en in de nabijheid van Paramaribo wordt door stadsbewoners heel wat aan Wintidans gedaan. Bijzonder berucht zijn de Pauluskreek en de Tawajari, afgelegen plaatsen, waar vaak groote partijen gegeven worden.

Zooals reeds boven is gezegd is niet ieder boschneger een goed medium. Het wordt als een bijzonder voorrecht

1) Alle daden die een bezeten persoon volbrengt zijn voor rekening van den geest, alle wenschen die gekoesterd worden moeten, wil men zich de wraak van den geest niet op den hals halen, vervuld worden. 
schap zijn geworden verdienen dezen hier nadere bespreking.

Zoo heb ik tevergeefs gezocht naar het mooie stelsel van de tusschengoden en ook de dienstvaardige heirscharen van geesten, die Ampoekoe en den Kromantigado behulpzaam moeten zijn, zijn mij gebleken de meest onregelmatige, ongedisciplineerde troepen te zijn waarover een geest kan gebieden.

De thans volgende bespreking van de vereering der voorouders vertoont ons een meer een geheel vormend, scherper omlijnd beeld der voorstellingen op dit gebied. De denkbeelden gevormd omtrent de Granjorka en jorka zijn bij alle boschnegers volkomen gelijk.

Geest en lichaam worden niet door den dood van elkaar gescheiden. Zoolang een onderdeel van het lichaam aanwezig is, zoolang vertoeft ook de geest daarin. Men brengt den geest van in den vreemde overleden boschnegers, verborgen in de haren en nagels, welke men van den doode afknipt, naar hun geboortegrond terug. en begraaft dezen met de voorstelling de geheele persoon begraven te hebben.

De jorka van een overleden persoon blijft al de karaktereigenschappen van deze behouden.

De jorka van eenen boschneger, die op aarde een voorbeeldig leven heeft geleid, wordt opgenomen bij de Granjorka.

De verblijfplaats der laatstgenoemden is gelegen nabij de woonplaats van Grangado. Aan dezen kunnen zij echter geene verzoeken overbrengen, zij kunnen Grangado niet naderen. Alle hulp welke de Granjorka aan de stamgenooten op aarde verleent vloeit voort uit de machtbeschikking hun door den schepper in het begin van het zijn verleend.

Heerscht nu ten opzichte van het hiervoren gezegde bij alle boschnegers volkomen overeenstemming zoo is dit niet het geval ten opzichte van het tijdstip waarop de jorka de woonplaats der voorouders binnentreedt. Terwijl ik vernam dat terstond na de begrafenis de jorka de reis aanvaardt hoorde ik weder van andere boschnegers 
dat zich de jorka eerst na drie maanden op den weg begeeft naar de verblijfplaats der Gransembe.

Vele boschnegers vertelden mij dat personen die als man en vrouw samen hebben geleefd eerst na volledige reiniging van de in leven gebleven persoon tot de voorouders worden toegelaten. Deze reiniging, feitelijk onder de gebruiken tehuis behoorende zal evenwel, omdat zij verband houdt met het geloof aan de voorouders, hier eene korte bespreking vinden.

Eene weduwe mag na het overlijden van haren man eerst gemeenschap met andere mannen hebben, nadat zij na verloop van zekeren tijd door een familielid van den overledene is gereinigd. Jonge vrouwen moeten tenminste zeven maanden onthouding beoefenen, terwijl meer bejaarde tot twee en meer jaren afzondering worden gedwongen.

Is de dag der reiniging eener vrouw gekomen dan wordt een der mannen van de familie van den overleden man aangewezen op den avond van dien dag zich naar de hut van de weduwe te begeven en haar aangezegd op dien avond zonder licht op te steken in hare hut te blijven. Tevens wordt haar bevolen in het geheel niet te spreken en zich vooral niet te verzetten tegen hetgeen gebeuren moet ${ }^{1}$ ).

Het aangewezen familielid dringt dezen avond de hut der weduwe binnen en oefent den coïtus met haar uit. Zonder een woord gesproken te hebben verwijdert hij zich weder. De geest van den overleden man der weduwe vormt van nu af geen gevaar meer voor de gemeenschap, hij is op weg naar de Gransembe.

Een man mag zich van den jorka van de vrouw waarmede hij geleefd heeft, niet bij eene vrouw van den stam reinigen. De Saramaccaners welke in deze omstandigheden verkeeren reizen naar Paramaribo en begeven zich aldaar naar eene publieke vrouw.

Op ieder dorp staan een of meer masten welke soms in

$\left.{ }^{2}\right)$ ) Mijwerd medegedeeld datdikwijls genoeg met deverlangensvanden een of anderen man (van de familie altijd) rekening wordt gehouden en dat beiden dan na de na te noemen handeling als man en vrouw blijven samenleven. 
den vorm van een kruis met elkaar zijn verbonden. Rondom dezen is òf een houten bak òf een rek aangebracht waarbinnen talrijke flesschen, kalebassen en kommetjes staan en liggen en lange stokken, aan welker uiteinde katoenen of calicolappen bij wijze van vlaggen zijn bevestigd, in den grond zijn gestoken.

Bij de Saramaccanen heet de plaats Grangadopaw (mast of boom van Grangado) ofschoon deze hoegenaamd niets met Grangado heeft uit te staan. De Aucaners duiden de plaats aan met fragatikki (vlaggestok).

Bij deze masten verleenen de voorouders te allen tijde audiëntie en hooren na ontvangst van eene offergave iedereen aan.

Ieder voorval van beteekenis, iedere nood wordt hier aan de Gransembe medegedeeld. In dagen van nood en zorg zoekt de boschneger hier verlichting. Als er niets anders is, in het bijzonder in deze slechte tijden, stellen zich de geesten met wat water tevreden, dat langzaam op den grond wordt uitgegoten. In gewichtiger aangelegenheden echter moet wat rum worden geofferd. Zoo geschiedde het in het begin van April van het jaar 1923, toen ik te Granmankondre was aangekomen. De oude kapitein Poko kwam uit de hut van den Granman met een heele flesch rum en begaf zich daarmede, gevolgd door een tiental andere kapiteins en boschnegers naar den Grangadopaw. Van uit de hut waarin mijne arbeiders gelogeerd waren, kon ik onbemerkt de geheele vertooning zien en ieder woord verstaan dat gesproken werd. Nadat allen op hunne bankjes gezeten waren, kuchtte Poko eenige malen en liet daarna den inhoud van een bitterglaasje langzaam op den grond uitloopen. Daarop begon hij mede te deelen, dat het gezelschap tot de Gransembe was gekomen om dezen te doen weten, dat Joenkoesoe naar de Saramacca was gekomen om met den Granman over de slechte tijden te spreken. Zooals de Gransembe wel wisten was de foeka groot bij hun volk. De blanke was echter niet te vertrouwen en daarom verzocht hij, Poko, het zoo te willen regelen, dat uit de komst van dezen voor de Saramaccaners geen onheil zoude voortvloeien. 
Poko sprak wel een half uur met de voorouders; telkens in herhalingen terugvallende, lette hij echter er op dat het bitterglaasje niet te vol werd geschonken en niet te vaak werd uitgestort.

Nadat mijne aangelegenheid was behandeld verscheen eene zwangere vrouw ten tooneele. Eene anderevrouw, hare schoonmoeder, had haar gevloekt en daardoor het jonge leven, dat zij onder het hart droeg in gevaar gebracht.

Poko liet de vrouw naast den mast staan en hare linkerhand tegen den mast houden. Haar gezicht was naar buiten gekeerd. De oude begon daarna op hartroerende wijze te verzoeken, dat de fioefioe ${ }^{\mathbf{1}}$ ) uit den buik der vrouw zouden worden weggenomen. Een vol glaasje bracht blijkbaar de Granjorkas in goede stemming. Poko stond op reikte aan de vrouw eene kalebas met water. Deze nam een flinke teug en spuwde het water weder uit, terwijl Poko verklaarde, dat de Granjorkas den vloek hadden weggenomen. Met een glimlachend, tevreden gelaat verliet de vrouw de plaats. De heeren bleven nog wat keuvelen met elkaar en maakten daarbij de groote rest van de flesch op.

Zooals zeker reeds is opgemerkt, wordt aan de voorouders geofferd. Keert een boschneger naar zijn dorp terug en is het hem bij den houthandel of op de marktvaart nogal mee geloopen, dan steekt hij bij den Grangadopaw eene nieuwe vlag uit of hij legt aan de voeten van den mast een flesch bier, swieti sopi (likeur) of in een kalebas andere lekkernijen neer.

De geesten der voorouders berokkenen nooit kwaad, zij onthouden de bewoners van een dorp wel soms hunne gunsten en wel in gevallen, dat door een of meerdere bewoners tegen de instellingen van den stam is gezondigd. Grootere offers verzoenen hen echter weder, in het bijzonder wanneer verdienstelijke mannen met deze offers hunne smeekbede vereenigen.

(Wordt vervolgd.)

1) fioefioe $=$ wandluis. Hier wordt echter bedoeld het magische gevaar dat door den vloek is ontstaan. Men is vast overtuigd, dat eene vrouw met fioefioe eene zeer slechte bevalling tegemoet gaat. Fioefioe kan ook ontstaan wanneer de naaste betrekkingen van eene zwangere vrouw met haar in slechte verhouding leven.

De voorstelling omtrent fioefioe is door geheel Suriname verspreid. 